\title{
Directed Self Assembly Material Development for Fine Patterning and Pattern Repair
}

\author{
Shinya Minegishi, Yuji Namie, Kenichi Izumi, Yusuke Anno, Xavier Buch, \\ Takehiko Naruoka, Yoshi Hishiro and Tomoki Nagai \\ Fine Electronic Research Laboratories \\ Semiconductor Materials Laboratory \\ JSR Corporation \\ 100, Kawajiri-cho, Yokkaichi Mie 510-8552 Japan
}

\begin{abstract}
The Directed Self-Assembly (DSA) method is becoming a key complementary technology for enabling lithographic pattern feature shrinkage. Recent DSA technology has developed remarkable improvements in many aspects of materials and process. Polystyreneb-polymethylmethacrylate (PS-b-PMMA) block copolymer (BCP) is a typical material used in DSA, but more advanced materials are required for achieving patterning less than $10 \mathrm{~nm}$ in size. High- $\chi$ block copolymers are being researched as next generation PS-b-PMMA material successors. Polymers with high- $\chi$ produce smaller pattern sizes than PS-b-PMMA. However, doing DSA with these high- $\chi$ materials requires a special method to separate one phase of BCP such as phase separation in solvent. We have done further research to improve high- $\chi$ materials to enable better DSA technology. Here we report $8.4 \mathrm{~nm}$ half-pitch line patterns were formed with our high- $\chi$ block co-polymer, annealing under air. DSA is a candidate for next generation lithography. However, DSA materials are not used alone. DSA materials are always used with guide pattern to "direct" self assembly materials. Currently ArF resist is well studied as guide pattern. ArF resist is extended to use further generation, but the required resolution level is already severe for $193 \mathrm{~nm}$ patterning. Employment of blend DSA could improve the ArF pattern profile.
\end{abstract}

Keyword: Directed self assembly, Next generation lithography, ArF extension, Pattern repair,

\section{Introduction}

The semiconductor industry has been developing the technologies and has been extended Moore's Law over 40 years [1,2]. According to Rayleigh's equation, shorter exposure wavelength and higher numerical aperture caused the higher resolution of lithography process [3]. When the exposure wavelength reached $193 \mathrm{~nm}$ and the NA went up to 1.35 with water immersion $\mathrm{ArF}$ lithography, the improvement of exposure wavelength and NA came to a temporary standstill. Further improvement of resolution was achieved with double patterning techniques, e.g. Self
Aligned Double Patterning [4] for 3x nm and 2x nm. Further size reduction requires triple or quadruple patterning, and it causes huge increase of $\mathrm{CoO}$ and the difficulty of overlay [5]

Extreme ultraviolet (EUV) lithography has been the favorite candidate of successor of immersion ArF [6-24]. Although EUV system is more expensive than the other traditional single patterning lithography systems and the development is relatively slower than other past exposure tool, EUV lithography is still the first candidate for next generation lithography.

Except EUV lithography, other lithography

\begin{tabular}{llr}
\hline Received & April & 30,2013 \\
Accepted & June & 3,2013
\end{tabular}


candidates, i.e., multi patterning, nanoimprint, mask less lithography, and DSA are also investigated. DSA appeared at ITRS road map in 2007 as lithography technology candidate for $16 \mathrm{~nm}$ generation [25]. A lot of work has been reported about DSA materials as sub-20nm or even sub-10nm patterning materials. DSA is expected not only as the resist materials but also as the resist support material [26-34]. Application of DSA materials may extend immersion $\mathrm{ArF}$ and support the rise of EUV.

In this paper we explain the detail of a PS-b-PMMA and new BCP patterning. And the pattern profile repair of $\mathrm{ArF}$ pattern was investigated with blend DSA material.

\section{Experimental}

\subsection{Materials}

DSA agents and neutral layers were prepared for each target pattern type and pattern size. JSR ArF resist, a methacrylate base $193 \mathrm{~nm}$ photoresist, was used throughout this study. JSR SiARC and SOC (spin on carbon) were spin-coated on bare silicon substrates as under layer of DSA. Aqueous, tetramethylammonium hydroxide (TMAH, 2.38 wt \%) was used for developing the photoresist. Deionized water (DIW) was used for the immersion exposures.

\subsection{Evaluation tools}

CLEAN TRACK LITHIUS i (TEL) or CLEAN TRACK ACT12 (TEL) was used for the DSA / neutral layer / photoresist / SiARC / SOC coating, bake and development processes. Exposure was carried out with an ASML XT1900i $(\mathrm{NA}=1.35)$ or NIKON S610 (NA=1.30). CD measurement and observation of top-down profile for each wafer was performed using the CD-SEM: CG-4000 (Hitachi High-Tech.)

\section{Results and Discussion}

\subsubsection{Sub $20 \mathrm{~nm}$ patterning by PS-b-PMMA}

BCP polymer gives various phase separation patterns. For example, the phase separation behavior of PS-b-PMMA is well studied [26-34], and currently it is the most common block co-polymer for DSA patterning. Following results are sub $20 \mathrm{~nm}$ patterning examples by PS-b-PMMA type DSA materials. Figure 1 shows $12.5 \mathrm{nmLS}$ patterning by chemo-epitaxy patterning process. This line pattern was obtained, ArF resist pattering, resist hardening process, neutral layer coating, resist lift-off, and PS-b-PMMA patterning [35].

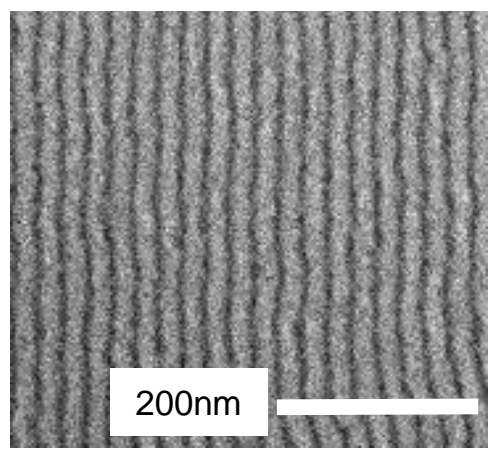

Figure $1.12 .5 \mathrm{nmLS}$ by Chemo-epitaxy process.

Sub 20nm LS can be patterned by ArF multi-patterning. Hole pattern also can be prepared by ArF multi patterning, however, the process will be much more complicated than line pattern and the process will be much more expensive. $\mathrm{CH}$ patterning of sub $20 \mathrm{~nm}$ is more immediate target for DSA. The following example is hole patterning with ArF guide pattern (Figure 2). At first $58 \mathrm{nmS} 90 \mathrm{nmP}$ pattern was prepared, and PS-b-PMMA was patterned with the guide. As the result, $15 \mathrm{~nm}$ hole pattern was prepared with aligned along LS guide pattern.

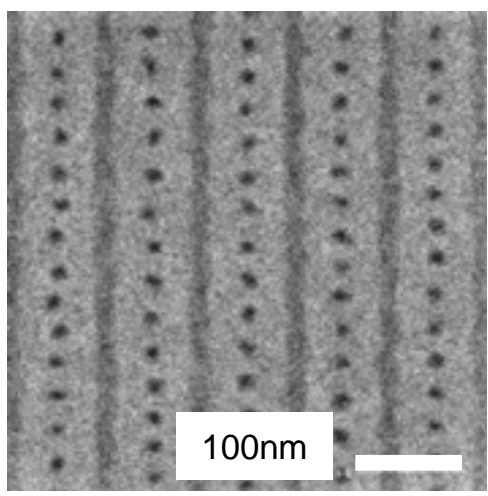

Figure 2. 15nmhole patterning

\subsubsection{Sub10nm patterning by BCP}

PS-b-PMMA is the most well studied BCP material for DSA lithography pattering. The $\chi$ parameter of PS-b-PMMA is about 0.04 [36], and based on Flory-Huggins theory, the smallest limit is $20-25 \mathrm{~nm}$ pitch. Figure 3 is the $20.8 \mathrm{~nm}$ pitch lamella pattern by PS-b-PMMA. For the smaller pattern, high-x material is necessary.

High $\chi$ BCP is being developed for below $10 \mathrm{~nm}$ patterning. High $\chi \mathrm{BCP}$ patterning is usually required the application of top-coat (TC) or solvent 


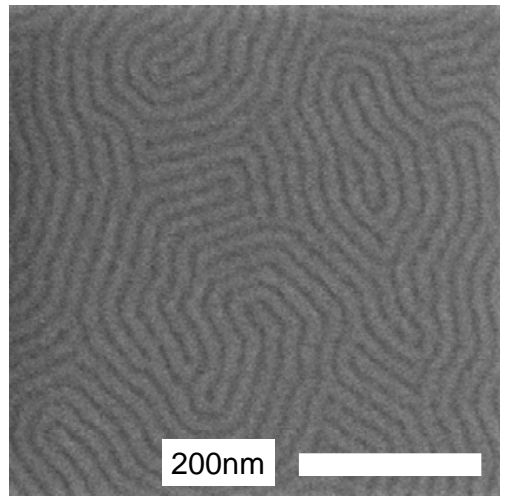

Figure

3. $20.8 \mathrm{~nm}$ lamella by PS-b-PMMA.

annealing [13]. We developed $8.4 \mathrm{~nm}$ line pattern forming with high $\chi \mathrm{BCP}$ at 220 degree in $60 \mathrm{~s}$ anneal under nitrogen, without TC process and solvent annealing (Figure 4). It is considerable that neutral layer (NL) was fitted both BCP units.

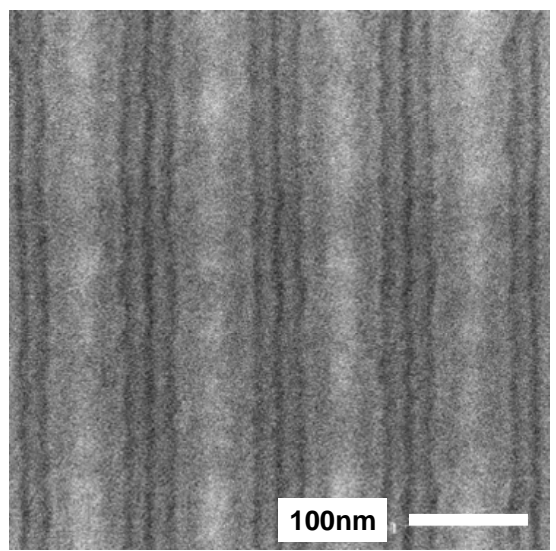

Figure 4. 8.4nmLS with high- $\chi$ BCP.

\subsection{Pattern profile repair by blend DSA}

DSA is a candidate for next generation lithography, however, DSA materials are not used alone. DSA materials are always used with guide pattern to "direct" self assembly materials. Currently ArF resist is well studied as guide pattern. ArF resist is extended to use further generation, but the required resolution level is already severe for $193 \mathrm{~nm}$ patterning, then the profile is not good enough even though small patterning is possible. DSA materials are also expected to repair pattern profile of ArF resist. The following is the example of pattern profile repair of $120 \mathrm{nmP} \mathrm{CH}$ ArF resist by blend type DSA. The target pattern is true circle, but the initial profile is almost square. The profile was improved after blend DSA treatment.

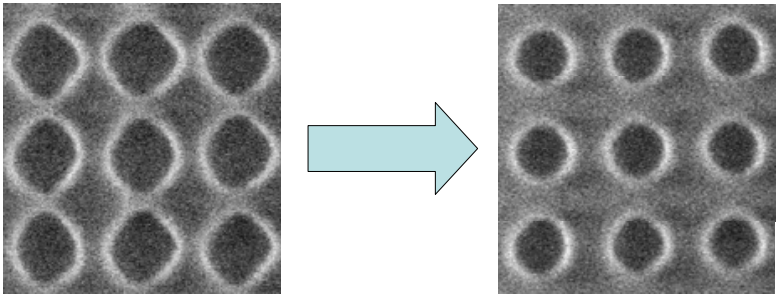

Figure 5. 120nmP pattern profile repair by blend DSA.

\section{Conclusion}

PS-b-PMMA is a typical material used in DSA, and sub $20 \mathrm{~nm}$ patterning was performed in this paper. But more advanced materials are required for achieving patterning less than $10 \mathrm{~nm}$ in size. Here we report $8.4 \mathrm{~nm}$ half-pitch line patterns were formed with our high- $\chi$ block co-polymer, annealing under air. Employment of blend DSA could improve the pattern profile.

\section{Acknowledgement}

The authors gratefully thank IMEC for their support of the experiment through use of their tools.

\section{References}

1. H. Ito, J. Photopolym. Sci. Tech., 20 (2007) 319.

2. H. Ito, J. Photopolym. Sci. Tech., 21 (2008), 475.

3. T. Furukawa, K. Hieda, Y. Wang, T. Miyamatsu, K. Yamada, T. Tominaga, Y. Makita, H. Nakagawa, A. Nakamura, M. Shima, T. Shimokawa, J. Photopolym. Sci. Tech., 19 (2006) 641.

4. H. Yaegashi, K. Oyama, K. Yabe, S. Yamauchi, A. Hara, S. Natori, J. Photopolym. Sci. Tech., 24 (2011) 491.

5. S. Kyoh, Y. Nakajima, S. Watanabe, T. Imamura, T. Sasaki, M. Omura, K. Tawarayama, K. Matsunaga, J. Photopolym. Sci. Tech., 24 (2011), 19.

6. D. Shimizu, K. Maruyama, A. Saitou, T. Kai, T. Shimokawa, K. Fujiwara, Y. Kikuchi, I. Nishiyama, J. Photopolym. Sci. Tech., 20 (2007) 423.

7. T. Kimura, K. Nishino, M. Shimizu, Y. Hirai, K. Maruyama, T. Kai, J. Photopolym. Sci. Tech., 23 (2010) 643.

8. T. Shioya, K. Maruyama, T. Kimura, J. Photopolym. Sci. Tech,. 24 (2011) 199. 
9. S. Tarutani, H. Tamaoki, H. Tsubaki, T. Takahashi, H. Takizawa, H. Takahashi, S.-J. Kang, J. Photopolym. Sci. Tech., 24 (2011) 185.

10. T. Yamashita, M. Morita, Y. Tanaka, J. J. Santillan, T. Itani, J. Photopolym. Sci. Tech., 24 (2011) 165.

11. S. Kruger, C. Higgins, C. Gallatin, R. Brainard, J. Photopolym. Sci. Tech., 24 (2011) 143.

12. M. Endo, S. Tagawa, J. Photopolym. Sci. Tech., 24 (2011) 205.

13. Y. Kikuchi, J. Photopolym. Sci. Tech., 24 (2011) 173.

14. J. W. Thackeray, V. J. Jain, S. Coley, M. Christianson, D. Arriola, P. LaBeaume, S.-J. Kang, M. Wagner, J. W. Sung, J. Cameron, J. Photopolym. Sci. Tech., 24 (2011) 179.

15. T. Urayama, T. Watanabe, Y. Yamaguchi, N. Matsuda, Y. Fukushima, T. Iguchi, T. Harada, H. Kinoshita, J. Photopolym. Sci. Tech., 24 (2011) 153.

16. T. Kozawa, S. Tagawa, J. Photopolym. Sci. Tech., 24 (2011) 173.

17. A. M. Goethals, A. Niroomand, F. V. Roey, K. Hosokawa, I. Pollentier, J. Photopolym. Sci. Tech., 24 (2011) 25.

18. T. Itani, J. Photopolym. Sci. Tech., 24 (2011) 111.

19. T. Nishikubo, H. Kudo, J. Photopolym. Sci. Tech., 24 (2011) 9.

20. W. Monttomery, B. Rice, R. Brilla, M. Liehr, M. Tittnich, J. Photopolym. Sci. Tech., 24 (2011) 193.

21. P. Naulleau, C. Anderson, S. George, J. Photopolym. Sci. Tech., 24 (2011) 637 (2011).

22. H. Yamamoto, T. Kozawa, S. Tagawa, T. Mimura, T. Iwai, J. Onodera, J. Photopolym. Sci. Tech., 24 (2011) 405.

23. G. J. Vandentop, E. S. Putna, M. J. Leeson, T. R. Younkin, G. M. Kloster, U. Shah, M.
Chandhok, J. Photopolym. Sci. Tech., 24 (2011) 127.

24. H.-W. Kim, H.-S. Na, C.-M. Park, C. Park, S. Kim, C. Koh, I.-S. Kim, H.-K. Cho, J. Photopolym. Sci. Tech., 24 (2011) 119.

25. http://www.itrs.net/

26. D. P. Sanders, J. Cheng, C. T. Rettner, W. D. Hinsberg, H.-C. Kim, H. Trung, A. Fritz, S. Harrer, S. Holmes, M. Colburn, J. Photopolym. Sci. Tech. 23 (2011) 11.

27. R. R. Dammel, J. Photopolym. Sci. Tech., 24 (2011) 33.

28. G. S. W. Craig, P. F. Nealey, J. Photopolym. Sci. Tech., 20 (2007) 511.

29. H. Yoshida, Y. Tada, Y. Ishida, T. Hayakawa, M. Takenaka, H. Hasegawa, J. Photopolym. Sci. Tech., 24 (2011) 577.

30. Y. Ishida, Y. Tada, T. Hirai, R. Goseki, M. Kakimoto, H. Yoshida, T. Hayakawa, J. Photopolym. Sci. Tech., 23 (2010) 155.

31. Y. Tada, S. Akasaka, F. Cheng, H. Yoshida, M. Takenaka, H. Hasegawa, J. Photopolym. Sci. Tech., 22 (2009), 229.

32. S. Hattori, K. Asakawa, S. Mikoshiba, H. Nakamura, A. Hieno, Y. Seino, M. Kanno, T. Azumam, J. Photopolym. Sci. Tech., 24 (2011) 581.

33. J. Y. Cheng, A. Nelson, C. T. Rettner, D. P. Sanders, A. Sutherland, J. W. Pitera, Y.-H. Na, H.-C. Kim, W. Hinsberg, J. Photopolym. Sci. Tech., 22 (2009) 219.

34. J. K. Bosworth, E. Dobisz, R. Ruiz, J. Photopolym. Sci. Tech., 23 (2010) 145.

35. J. Y. Cheng, D. P. Sanders, H. D. Truong, S. Harrer, A. Friz, S. Holmes, M. Colburn, W. D. Hinsberza, ACS Nano, 4 (2010) 4815.

36. T. Seshimo, C. M. Bates, L. M. Dean, J. D. Cushen, W. J. Durand, M. J. Maher, C. J. Ellison, C. G. Willson, J. Photopolym. Sci. Tech., 23 (2010) 145 